\title{
Cell-based polymerase chain reaction for canine transmissible venereal tumor (CTVT) diagnosis
}

\author{
Chanokchon SETTHAWONGSIN ${ }^{1}$, Somporn TECHANGAMSUWAN ${ }^{1}$, Sirikachorn TANGKAWATTANA ${ }^{2)}$ and \\ Anudep RUNGSIPIPAT ${ }^{1) *}$ \\ ${ }^{1)}$ Companion Animal Cancer Research Unit, Department of Pathology, Faculty of Veterinary Science, Chulalongkorn University, \\ Bangkok, 10330, Thailand \\ ${ }^{2)}$ Department of Veterinary Pathobiology, Faculty of Veterinary Medicine, Khon Kaen University, Khon Kaen, 40002, Thailand
}

(Received 22 December 2015/Accepted 1 April 2016/Published online in J-STAGE 14 April 2016)

\begin{abstract}
Canine transmissible venereal tumor (CTVT) is the only naturally contagious tumor that is transmitted during coitus or social behaviors. Based on the tumor's location, the diagnosis of genital TVT (GTVT) is comparably easier than those in the extragenital area (ETVT) that are more easily incorrectly diagnosed. Fortunately, CTVT cells contain a specific long interspersed nuclear elements (LINE), inserted upstream of the $m y c$ gene, allowing a diagnostic polymerase chain reaction (PCR) based detection assay. The objectives of this study were aimed to improve the diagnostic accuracy by applying the diagnostic LINE1-c-myc PCR assay and fine needle aspiration (FNA) collection in direct comparison with standard cytological and histopathological analyses. Seventy-four dogs, comprised of 41 and 31 dogs with tumor masses at their external genitalia and extragenital areas (e.g. skin and nasal cavity), respectively, were included in this study. The signalment of these $65 \mathrm{dogs}$ and clinical history of 20 client-owned dogs were collected. Samples were taken by biopsy for both histopathological examination and FNA for cytological examination and diagnostic PCR. The PCR products from 10 apparently CTVT samples were purified and sequenced. Sixty-one CTVT cases were diagnosed by cytological and histological analyses, but 65 were positive by the PCR assay. Overall, the PCR assay improved the accuracy of diagnostic CTVT results, especially for the more difficult ETVT tumors. Moreover, this PCR-based approach can facilitate the decision as to discontinue chemotherapy by discrimination between residual tumor cell masses and fibrotic tissue.
\end{abstract}

KEY words: CTVT, diagnosis, FNA, LINE, PCR

doi: 10.1292/jvms.15-0710; J. Vet. Med. Sci. 78(7): 1167-1173, 2016

Canine transmissible venereal tumor (CTVT) is an important contagious tumor in tropical and subtropical countries. It is usually transmitted by viable cancer cells from CTVT dogs to susceptible hosts during coitus or other social behaviors [5]. The tumors are mostly located in the external genital area; of the vulva and penis, but they are also found in other parts of the body, such as skin, eyes, nasal cavity and oral mucosa $[10,12,15,17]$. The metastasis potential is quite rare, but can occur in immunosuppressed dogs $[5,9]$.

Canine TVT is classified into two types according to its anatomical location, namely; genital TVT (GTVT) and extragenital TVT (ETVT). For GTVT, it is easy to diagnose from its location and cauliflower-like mass feature, but diagnosis of ETVT is more ambiguous due to the button-like mass in skin form or the appearance of the nasal and oral masses. Since CTVT is a round cell tumor, it needs differential diagnosis from other round cell tumors, such as mast cell tumor, histiocytic tumor, lymphoma, etc., amelanotic melanoma and other poorly differentiated carcinomas [16].

*Correspondence to: Rungsipipat A., Companion Animal Cancer Research Unit, Department of Pathology, Faculty of Veterinary Science, Chulalongkorn University, Bangkok, 10330, Thailand. e-mail: Anudep.r@chula.ac.th

(C)2016 The Japanese Society of Veterinary Science

This is an open-access article distributed under the terms of the Creative Commons Attribution Non-Commercial No Derivatives (by-nc-nd) License $<$ http://creativecommons.org/licenses/by-nc-nd/4.0/>.
The use of conventional, cytological and histopathological analyses, only cannot confirm a CTVT diagnosis, if their feature is different from their normal appearance. In addition, CTVTs also share the same origin as histiocytic tumors, so immunohistochemistry (IHC) cannot make a definitive diagnosis $[5,11]$. Fortunately, CTVT has a unique molecular characteristic based around a c-myc gene re-arrangement that is absent in normal somatic cells and gametes, and other tumor cells [7]. This rearrangement is derived from the insertion of a long interspersed nuclear element (LINE) or long interspersed repeated DNA element, retroposon element [1] that shows a $98 \%$ homology to the canine LINE-1 $[3,4]$. Thus, the presence of this LINE element near c-myc (LINE-c-myc) has been used as a diagnostic tool to make a definitive diagnosis of CTVT cases using in situ polymerase chain reaction (PCR) and conventional PCR in controversial cases $[8,16]$.

Within Bangkok (Capital city of Thailand), CTVT is the most common reproductive tumor of dogs, regardless of their sex and age [19]. The specific climate and poor policy of controlling stray dogs in Thailand tend to increase the number of CTVT-bearing dogs, not only for GTVT but also for ETVT. Therefore, an accurate, rapid and reliable diagnostic tool is needed for therapeutic planning. This study aimed to improve the diagnostic accuracy of CTVT by applying the LINE-c-myc PCR assay on cell-based samples and to also provide an optimal sample collection for PCR using fine needle aspiration (FNA) to derive cell samples for additional 
cytological and histopathological analyses.

\section{MATERIALS AND METHODS}

Animals: Seventy-four tumor-bearing dogs (cases 1 to 74), regardless of their sex, breeds or age, were included in this prospective study, according to only the inclusion criteria that the tumors were located in the i.) external genital area (vulva, vagina or perineum in females and penis, prepuce or scrotum in males) or ii.) extra-genital areas, such as the skin, nasal or oral cavity. Signalments (sex, age and breed), anatomical site of the lesion mass and the owner status were recorded along with, for those dogs with an owner, the clinical history of any previous chemotherapy. All dogs were subjected to a complete physical examination at the Oncology Unit, Small Animal Teaching Hospital, Faculty of Veterinary Science, Chulalongkorn University, Thailand.

Sample collections: All dogs were intramuscularly injected with tiletamine-zolazepam (Zoletil ${ }^{\circledR}$, Virbac, Carros, France, at a dosage of 3-7 mg/kg) and locally anesthetized with $1 \%$ lidocaine $\mathrm{HCl}$ (Locana, L.B.S. laboratory Ltd., Bangkok, Thailand, at a dosage of $0.5-1 \mathrm{~m} / / \mathrm{site}$ ) in the tissue sampling region. After biopsy, the tissue was impressed on glass slides for cytological examination. Each tissue sample was halved, with one piece being preserved in $10 \%$ $(\mathrm{w} / \mathrm{v})$ neutral buffered formalin for routine histopathological diagnosis and the another piece being kept in a sterile eppendorf at $-80^{\circ} \mathrm{C}$ for the LINE1-c-myc PCR-based detection of CTVT. In addition, FNA-cells were also collected and kept in sterile PBS at $-80^{\circ} \mathrm{C}$ until used for the molecular and histological diagnoses of CTVT. All sampling procedures were approved by the Chulalongkorn University Animal Care and Use Committee (No. 133100077), and the dog's owners agreed to sign the consent form.

Cytology and histopathology examinations: Impression slides were left to dry in the open air, fixed with methanol and stained with Giemsa (Merck, Darmstadt, German) or Dip quick $^{\circledR}$ (Clinag Co., Ltd., Bangkok, Thailand) staining protocol. For formalin fixed tissues, they were subjected to routinely histological process and stained with hematoxylin and eosin (H\&E). All specimens were examined under light microscopy by pathologists. Each sample was examined independently by three pathologists to make a descriptive analysis. Cases of CTVT cases were diagnosed based on cell morphology following cytological and histopathological analyses. In addition, IHC was performed using cytokeratin (CK; Dako, Glostrup, Denmark) for confirmation of squamous cell carcinoma (SCC) and basal cell tumor, vimentin (Dako) and lysozyme (Dako) to confirm histiocytic tumor, Melan-A (Dako) to confirm malignant melanoma, CD3 (Leica, Newcastle upon Tyne, U.K.) and PAX-5 (Leica) to confirm lymphoma (LSA) and by toluidine blue staining to confirm mast cell tumor.

The LINE1-c-myc PCR assay: Total genomic DNA was extracted from FNA-derived cells and fresh tissue using Mammalian genomic DNA miniprep kit (Sigma-Aldrich, St. Louis, MO, U.S.A.) following the manufacturer's instruction. The DNA quantity and quality were measured using a NanoDrop Lite spectrophotometer (Thermo Fisher Scientific Inc., Wilmington, DE, U.S.A.). The primer pair specific to the region of the LINE-c-myc gene re-arrangement MycS-2 (5'-ATTCCTACGAATGAATGATTGGCCAGA-3') and LINE AS-1 (5'-CAGACACATAGATCAGTGGAACAGAAT-3') were used as previously described [8].

The PCR reaction contained 100-200 ng DNA, $10 \mu \mathrm{M}$ of each primer and GoTaq ${ }^{\circledR}$ Green Master Mix (Promega, Madison, WI, U.S.A.). The PCR thermal cycling consisted of 35 cycles of $94^{\circ} \mathrm{C}$ for $1 \mathrm{~min}$ (denaturation), $64^{\circ} \mathrm{C}$ for 50 sec (annealing) and $72^{\circ} \mathrm{C}$ for $1 \mathrm{~min}$ (extension). The PCR products (desired amplicon was $550 \mathrm{bp}$ ) were then resolved using $1.5 \%(\mathrm{w} / \mathrm{v})$ agarose gel electrophoresis and visualized by UV-transillumination after staining with $10 \%(\mathrm{w} / \mathrm{v})$ ethidium bromide. Negative and positive controls, respectively, were sterile water in place of the sample DNA extract and a GTVT sample previously diagnosed by both histopathology and PCR. The specificity of the LINE1-c-myc PCR assay for CTVT detection was determined by incorporation of other tumors, such as amelanotic melanoma, histiocytoma, basal cell tumor, lymphoma, mast cell tumor, squamous cell carcinoma (SCC) and chronic inflammatory tissue, in the screening process. The dynamic range of detectable DNA was ascertained by performing ten-fold dilution of positive control sample.

Phylogenetic analysis: Ten positive PCR products, from five FNA-derived samples, case 1 (CTVT-THC3), case 2 (CTVT-THC4), case 7 (CTVT-THC10), case 8 (CTVTTH-C14) and case 11 (sample from Dog No 1 in Table 2, CTVT-THC13) and five fresh tissue samples, case 4 (CTVTTHF1), case 5 from skin mass (CTVT-THF3), case 5 from penile mass (CTVT-THF4), case 6 (CTVT-THF5) and case 10 (CTVT-THF6), from different sites of anatomical lesion (ETVT or GTVT), were purified using NucleoSpin Extract II (Machinery-Nagel, Düren, Germany) and submitted for commercial sequencing (Solgent, Daejeon, Korea). Thereafter, sequences were analyzed, aligned and compared with the deposited sequences in the GenBank database using the BLASTn search algorithm. A phylogenetic tree was constructed from the aligned sequences using the MEGA 5 software package by means of the Maximum Likelihood (ML) algorithm. Standard error was calculated by the bootstrap method using 1,000 replicates. All sequences were submitted to GenBank, with their respective accession codes given in Fig.4.

Data analysis: Descriptive analysis was performed for the signalments data (sex, age and breed), clinical information (anatomical site of the lesion mass, owner status and clinical history of previous chemotherapy) and the results from the cytological, histological and phylogenetic analyses. The sensitivity, specificity, positive predictive value (PPV) and negative predictive value (NPV) were calculated and comparatively evaluated among each method.

\section{RESULTS}

Detection of CTVT by the LINE1-c-myc PCR assay: To confirm the presence of CTVT, genomic DNA from fresh tis- 
Table 1. Diagnostic result of CTVT status derived from the cytology, histopathology, IHC and LINE-c-myc PCR assay

\begin{tabular}{|c|c|c|c|c|c|}
\hline Type of tumor & $\begin{array}{c}\text { Cytology } \\
(\mathrm{n}=74)\end{array}$ & $\begin{array}{l}\text { Histopathology } \\
\qquad\left(\mathrm{n}=72^{\mathrm{a}}\right)\end{array}$ & IHC/Special stain & PCR & Definitive diagnosis $(\mathrm{n}=74)$ \\
\hline CTVT & 61 & 61 & & $62 \mathrm{PCR}(+)$ & CTVT 62 cases \\
\hline \multirow[t]{3}{*}{ Histiocytic sarcoma (HS) } & 4 & 4 & 4 Vimentin $(+)$ & $1 \mathrm{PCR}(+)$ & CTVT 1 case \\
\hline & & & 3 Lysozyme $(+)$ & $3 \operatorname{PCR}(-)$ & HS 3 cases \\
\hline & & & $4 \mathrm{CK}(-)$ & & \\
\hline \multirow[t]{3}{*}{ Histiocytoma } & 1 & 1 & 1 Vimentin $(+)$ & $1 \mathrm{PCR}(+)$ & CTVT 1 case \\
\hline & & & 1 Lysozyme $(+)$ & & \\
\hline & & & $1 \mathrm{CK}(-)$ & & \\
\hline \multirow[t]{2}{*}{ Squamous cell carcinoma (SCC) } & 2 & 1 & 1 Vimentin $(+)$ & $1 \mathrm{PCR}(+)$ & CTVT 1 case \\
\hline & & & $1 \mathrm{CK}(-)$ & $1 \mathrm{PCR}(-)$ & SCC 1 case \\
\hline Basal cell tumor & 1 & 1 & $1 \mathrm{CK}(+)$ & $1 \mathrm{PCR}(-)$ & Basal cell tumor 1 case \\
\hline \multirow[t]{2}{*}{ Lymphoma (LSA) } & 1 & 1 & CD3 $(+)$ & $1 \operatorname{PCR}(-)$ & LSA 1 case \\
\hline & & & PAX-5 (-) & & \\
\hline Chronic inflammation of skin & 2 & 1 & & $1 \operatorname{PCR}(-)$ & chronic inflammation 1 case \\
\hline Mast cell tumor (MCT) & 1 & 1 & Toluidine blue $(+)$ & $1 \mathrm{PCR}(-)$ & MCT 1 case \\
\hline Melanoma & 1 & 1 & Melan-A $(+)$ & $1 \mathrm{PCR}(-)$ & Melanoma 1 case \\
\hline
\end{tabular}

a) Tissues from 2 cases were unavailable for histopathological examination.

Table 2. Controversial results from the different CTVT diagnostic methods

\begin{tabular}{|c|c|c|c|c|c|c|c|c|c|}
\hline \multirow{2}{*}{ Case } & \multirow{2}{*}{$\operatorname{Sex}^{\mathrm{a})}$} & \multirow{2}{*}{$\begin{array}{c}\text { Age } \\
\text { (year) }\end{array}$} & \multirow{2}{*}{ Area } & \multirow{2}{*}{ Cytology } & \multirow{2}{*}{ Histopathology } & \multirow{2}{*}{$\mathrm{IHC}$} & \multicolumn{2}{|r|}{ PCR } & \multirow{2}{*}{$\begin{array}{c}\text { Final } \\
\text { Diagnosis }\end{array}$} \\
\hline & & & & & & & Fresh tissue & Cell derived FNA & \\
\hline 11 & M & 4 & Nasal cavity & Chronic inflammation & $\mathrm{N} / \mathrm{A}^{\mathrm{b})}$ & & $\mathrm{N} / \mathrm{A}^{\mathrm{b})}$ & $(+)$ & ETVT \\
\hline 12 & $\mathrm{~F}$ & 12 & Rectum & $\mathrm{SCC}$ & ETVT & $\begin{array}{l}\text { Vimentin (+) } \\
\mathrm{CK}(-)\end{array}$ & $(+)$ & $(+)$ & ETVT \\
\hline 16 & M & 3 & Skin & Histiocytoma & Histiocytoma & $\begin{array}{l}\text { Vimentin (+) } \\
\text { CK (-) } \\
\text { Lysozyme (-) }\end{array}$ & $(+)$ & $(+)$ & ETVT \\
\hline 24 & M & 5 & Skin & $\begin{array}{l}\text { Histiocytic } \\
\text { sarcoma }\end{array}$ & $\begin{array}{l}\text { Histiocytic } \\
\text { sarcoma }\end{array}$ & $\begin{array}{l}\text { Vimentin (+) } \\
\text { CK }(-) \\
\text { Lysozyme (-) }\end{array}$ & $\mathrm{N} / \mathrm{A}^{\mathrm{b})}$ & $(+)$ & ETVT \\
\hline
\end{tabular}

a) F; female, M; male. b) N/A; tissue for histopathology was not available.

sue and/ or cell-derived FNA samples $(n=74)$ was evaluated by the LINE1-c-myc PCR assay. Only TVT cases were successfully amplified with these specific primer, yielding the expected 550-bp amplicons (Fig. 1), while the other tested tumor types of histiocytic sarcoma, histiocytoma, SCC, basal cell carcinoma, lymphoma, mast cell tumor, amelanotic melanoma and chronic inflammation of skin, were all negative. The minimum detectable DNA level was $10 \mathrm{ng}$, as determined by performing ten-fold dilutions of the positive control sample (data not shown).

Cytology, histopathology, IHC and LINE1-c-myc PCR: Out of the 74 cases examined, 61 were diagnosed as CTVT positive by cytological examination (Table 1). However, controversial results were noted in case 12 which was diagnosed as SCC by cytology (Fig. 2) as the tumor cells were pleomorphic with large sized cells resembled epithelial cells. Conversely, after performing histopathological and IHC analyses, the final diagnosis was changed to ETVT because the tumor cells were arranged in a sheath pattern as a round cell tumor, while IHC showed that the tumor cells were positive for vimentin and negative for cytokeratin (CK).
The cases initially diagnosed as CTVT by the cytological and histopathological analyses were found to be positive by the PCR analysis, in terms of the presence of the expected 550 bp amplicon (Fig. 1). Interestingly, case 16 and case 24 (Table 2), which were diagnosed as histiocytic derived cancers by the histopathological analysis and were positive for vimentin and negative for CK by IHC analysis, were also found to be CTVT by the LINE1-c-myc PCR analysis of their FNA derived cell samples. These two cases were finally diagnosed as ETVT (Fig. 3). The cytology and histopathology of case 16 are shown in Fig. 2B and 2D, respectively.

The DNA sequences of the respective amplicons from fresh tissues and cell-derived FNA samples revealed 80-98\% and $96-100 \%$ homology to previous sequences, respectively. The ML phylogenetic analysis revealed a high similarity between the samples in this study and those from previous studies available in the Genbank database (Fig. 4). The samples (Genbank accession numbers in parenthesis), case 1 (KU680469), case 2 (KU680470), case 7 (KU680471), case11 (KU680472) and case 8 (KU680473), were cellderived FNA samples. In addition, case 4 (KU680474) and 


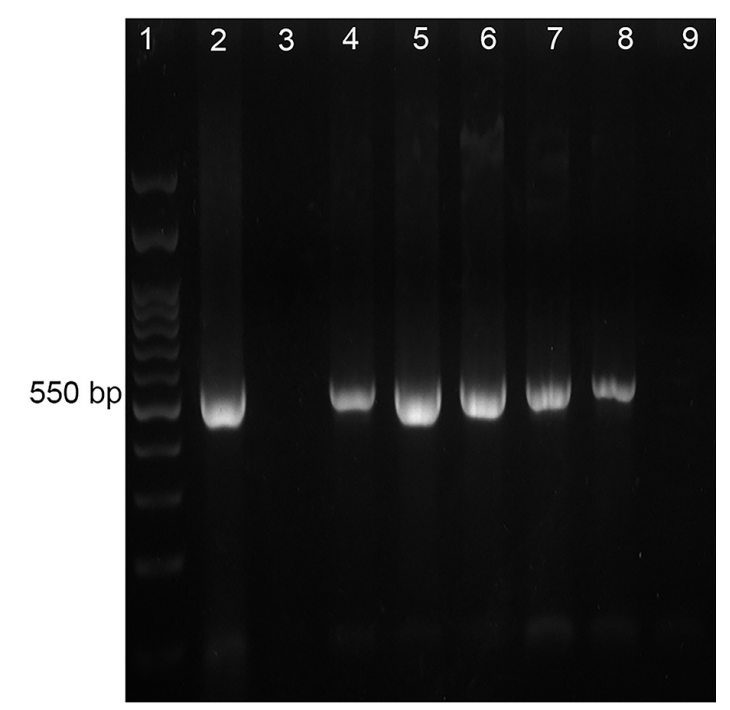

Fig. 1. PCR detection of the LINE1-c-myc gene rearrangement of CTVT origin from cell-derived FNA samples. PCR products $(550 \mathrm{bp})$ were resolved on a $1.5 \%(\mathrm{w} / \mathrm{v})$ agarose gel. (Lane $1=100$ bp DNA marker, Lane 2=positive control, Lane $3=$ negative control, Lanes 4-9 are samples from the vaginal mass (case 1), skin mass (case 2), nasal mass (case 7), nasal mass (case 8), nasal mass (case 11 in Table 2) and chronic inflammation tissue (case 9), respectively.)

case 5 from skin mass (KU680475), case 5 from penile mass (KU680476), case 6 (KU680477) and case 10 (KU680478) were from fresh tissue samples.

Sensitivity, specificity, PPV and NPV among diagnostic modalities: The LINE1-c-myc PCR had a diagnostic sensitivity and NPV of $100 \%$ and a specificity and PPV of over 80\% (Table 3).

Signalments and clinical information of CTVT dogs: From the 65 CTVT bearing dogs, as determined by the LINE1c-myc PCR assay, the majority were $2-5$ old $(61.8 \%)$ and intact genitalia males (40.0\%). Mongrel (95.4\%) and homeless $(69.2 \%)$ dogs were the main categories of dogs in this group. The TVTs were located at the external genital area (GTVT; 60.0\%) more often than at the extragenital area (ETVT; 40.0\%). The most common sites of ETVT were at the skin $(46.2 \%)$, nasal cavity $(34.6 \%)$, lymph node $(11.5 \%)$, oral cavity $(3.9 \%)$ and rectum $(3.9 \%)$. Among them, four dogs $(6.2 \%)$ had previously been treated with vincristine sulfate (VCL) intravenously with no response and so were considered to have VCL-resistant TVT (Table 4).

\section{DISCUSSION}

Sixty-five samples of dogs showed the previously reported [8] specific 550 bp LINE-c-myc PCR product and so were diagnosed as CTVT. Phylogenetic analysis of the specific $550 \mathrm{bp}$ amplicons from 10 of these samples revealed a high similarity to those in the Genbank database for CTVT samples from Israel, Taiwan and Japan (Fig. 4). There was no difference in the sample clustering between the different tumor anatomical sites (GTVT and ETVT) or known (normal and VCL-resistant CTVT cells). One possible explanation is that the molecular characteristic of CTVT in Thailand has the same clonal origin as CTVT cases all around the world [14], since this feature is found in normal and VCL-resistant CTVT cells.

Clinically, CTVT is recognized by its morphological features and location at the external genital area. However, those CTVTs in the extragenital mass are controversial and hard to diagnose. The LINE-c-myc gene rearrangement in the CTVT genome, which the PCR based diagnostic assay is based on, is the only thing that is consistently different from other tumor and normal dog cells, so detection of the LINE-c-myc gene rearrangement by PCR is a potential diagnostic tool for CTVT $[8,14]$. This study aimed to improve the accuracy of CTVT diagnosis by applying conventional, cytological and histological analyses, along with the PCR based LINE-c-myc detection assay to remove the ambiguity of imprecise CTVT diagnosis, especially for round cell tumors. The results support that this PCR assay could make a definitive diagnosis for all CTVT cases. Moreover, the advantage of the PCR assay was its sensitivity (10 $\mathrm{ng}$ of DNA), which is important for detection in the nasal cavity mass or at other sites where a biopsy is difficult to perform, since the FNA yields enough cells for the PCR assay. Sensitivity of this assay can get PCR result when use only $10 \mathrm{ng}$ of CTVT DNA.

The majority of the 65 CTVT dogs in this study were 2-5 years old and with intact genitals (not castrated or spayed). The age is related to the route of transmission via coitus or other social behavior, in that intact and mature dogs may have a relatively high sexual activity $[5,12]$ and so exposure risk. Nearly all of the CTVT dogs in this study were mongrel breed $(62 / 65)$, consistent with but not conclusive for the previous study that homeless dogs or mixed breed dogs seem to be exposed to CTVT to higher level and the tumor is usually located in the genital area $[1,3,4]$. Interestingly, the higher number of ETVT cases found in this study (40.0\%) reveals the help to clinicians in achieving an accurate diagnosis.

Normally, the CTVT cell morphology is uniformly round to polyhedral shaped cells with a central or eccentrical nucleus, prominent nucleoli, a vacuolated cytoplasm and moderate mitotic figures [13]. Canine histiocytoma is also a round cell tumor that contains a vacuolated cytoplasm [6], and so with these similar characteristics. It is possible that ETVT may be misdiagnosed as a histiocytoma by cytological and histological analyses without the LINE-c-myc based PCR assay, as seen in case 16 in this study (Table 2). From the cytology, the ETVT cells were pleomorphic round to ovoid shaped cells, with eccentrically amphophilic round to ovoid nuclei and a moderate amount of cytoplasm. Some cells contained small vacuoles in the cytoplasm (Fig. 2B). Indeed, previous reports have shown no difference between the IHC characteristics of histiocytoma and CTVT $[5,11$, $12,16]$. Surprisingly, these tumor cells were negative result for lysozyme, but give a clear diagnostic result in the LINEc-myc PCR assay and so were diagnosed as ETVT. Thus, this PCR assay can be used as a definitive diagnostic tool. 


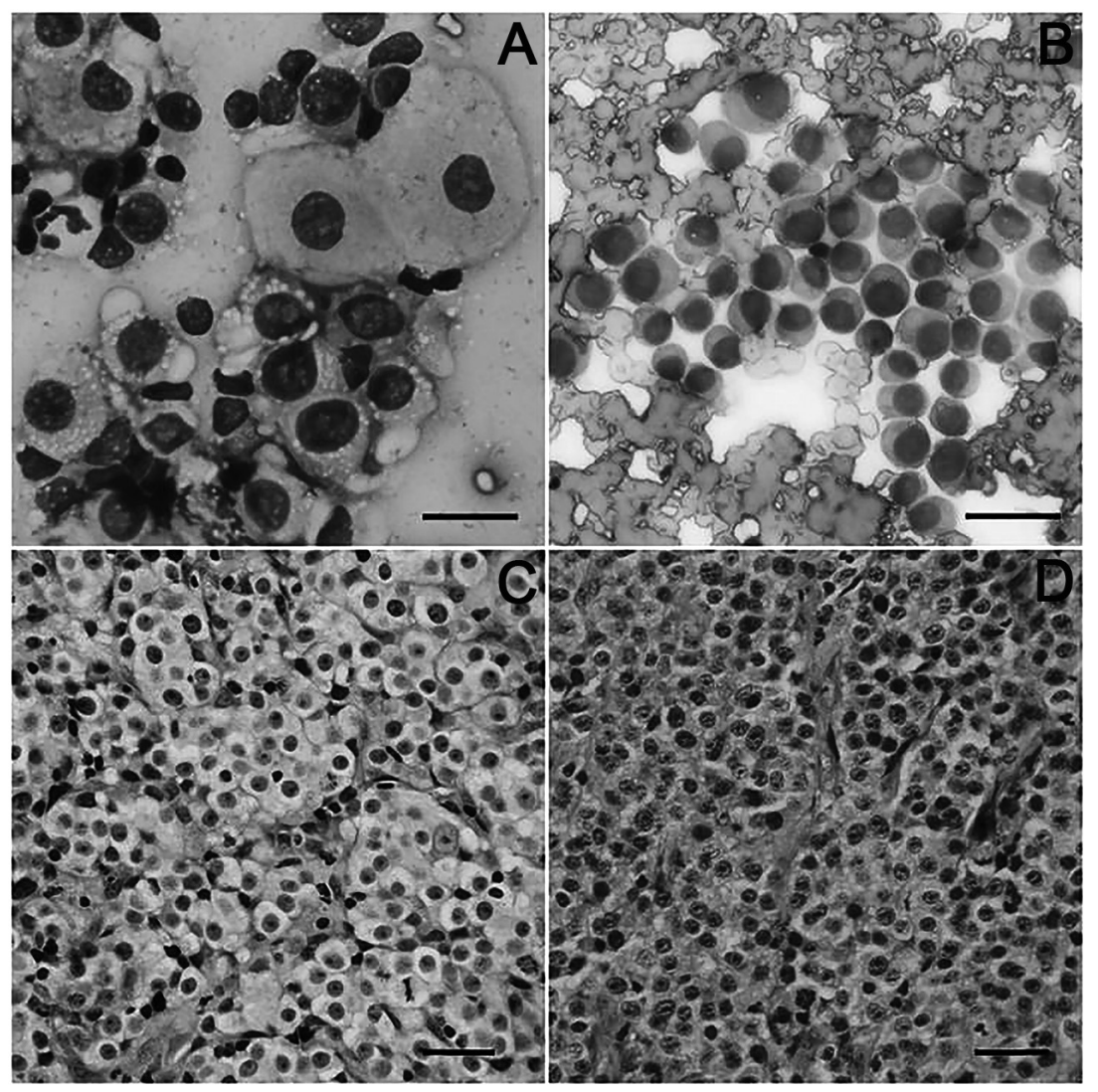

Fig. 2. Cytology $(40 \times)$ and histopathology $(40 \times)$ of the tumor mass stained with Giemsa stain and H\&E stain, respectively. Tumor cells from (A) case 12 in Table 2 with pleomorphic round to ovoid cells, moderate to large ovoid amphophilic nuclei, abundant pale basophilic cytoplasm and vacuolated, (B) case 16 in Table 2 with pleomorphic round to ovoid cells, round to ovoid eccentrically and centrically amphophilic nuclei and some cells with vacuoles in the cytoplasm, (C) case 12 with pleomorphic round to ovoid shaped cells arranged in a solid sheath pattern, amphophilic nucleoli and a clear pale cytoplasm, and (D) case 16 with a moderate pale cytoplasm and round to ovoid amphophilic nuclei. Mitotic figures were seen. Bar $=25 \mu \mathrm{m}$.

In contrast to a previous study, some samples had larger (e.g. case 12, Table 2) that looked like squamous cells. In addition to CTVT cells, lymphoma is round cell tumors and similar to histiocytic tumors. To make a definitive diagnosis of lymphoma, IHC analysis with CD3 and PAX-5 antibodies will need to be performed along with the LINE-c-myc PCR assay $[2,18]$.

Nevertheless, a false negative result or ladder feature of the PCR reaction may be found, which is probably caused by impropriate sample collection and DNA degradation during storage. Due to the small sample size in this study, further sample collection and analysis are required to make an accurate diagnosis protocol or method for other tumors. However, at present, we suggest that the LINE1-c-myc PCR assay can be used for definitive CTVT diagnosis in conjunction with and not as a replacement for the conventional cytological and histopathological, based analyses. The advantages of this diagnostic PCR assay in requiring a low amount of DNA, and hence a relatively low number of cells, could be applied to diagnose cases where only a small amount of sample could be collected or any other reason that prevents

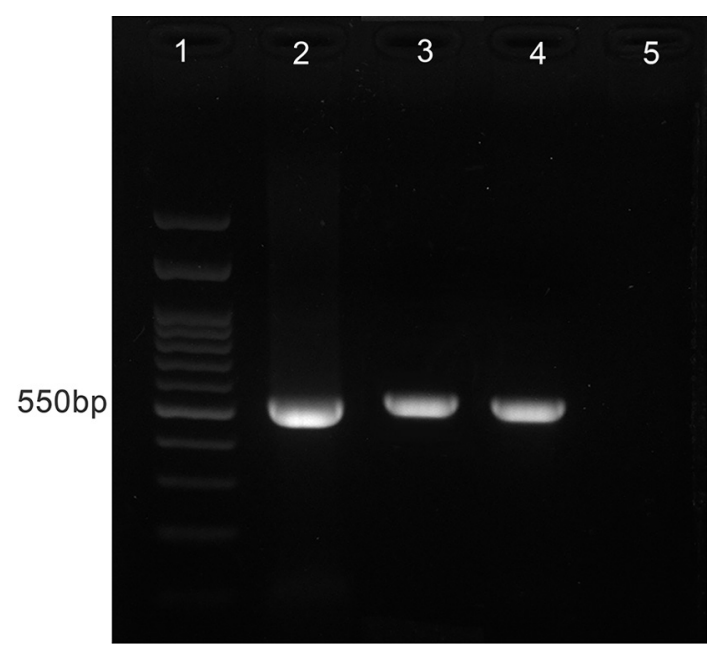

Fig. 3. PCR detection of the LINE1-c-myc gene from cell-derived FNA samples (cases 12 and 24, Table 2). PCR products (550 bp) were resolved on a $1.5 \%(\mathrm{w} / \mathrm{v})$ agarose gel. (Lane1=100-bp DNA marker, Lane 2 =positive control, Lane $3=$ case 12, Lane $4=$ case 24 and Lane 5 =negative control) 


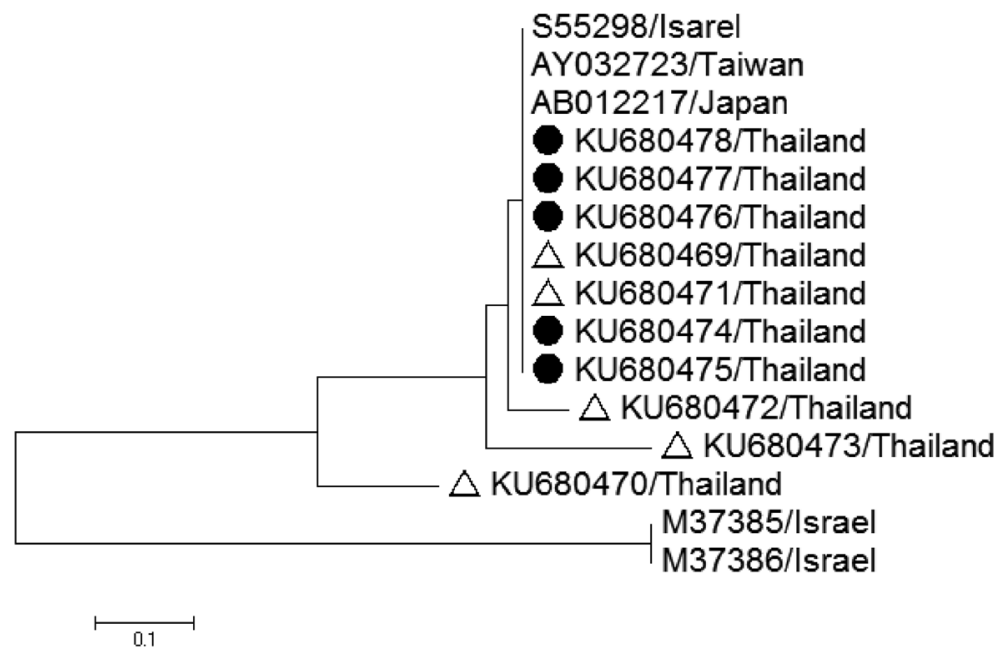

Fig. 4. Phylogenetic tree of the LINE-c-myc CTVT sequence of this study and the related sequences from the Genbank database. CTVT from Thailand sequences: FNA sample (triangle) sequences of KU680469 (case 1), KU680470 (case 2), KU680471 (case 7), KU680472 (case 11 in Table 2) and KU680473 (case 8); and fresh tissue samples (circle) from KU680474 (case 4), KU680475 (case 5, skin mass), KU680476 (case 5, penile mass), KU680477 (case 6) and KU680478 (case 10). CTVT samples in Genbank: Canis lupus familiaris LINE-1 elememt DNA partial sequence (AB012217), LINE/c-myc junction sequence (S55298), Canis familiaris c-myc gene partial sequence (AY032723), Dog c-myc oncogene DNA with a retroposon insertion target sequence (M37386) and Dog c-myc oncogene with an inserted retroposon (M37385).

Table 3. Comparison between PCR and conventional method (cytology and histopathology)

\begin{tabular}{lccccccc}
\hline & \multicolumn{3}{c}{ Cytology } & & \multicolumn{3}{c}{ Histopathology } \\
\cline { 2 - 4 } \cline { 6 - 7 } & Positive & Negative & Total & & Positive & Negative & Total \\
\hline PCR Positive & 61 & 4 & 65 & & 61 & 2 & 63 \\
assay Negative & 0 & 9 & 9 & & 9 & 9 \\
Total & 61 & 13 & 74 & & 61 & 11 & 72 \\
Sensitivity & & $100.0 \%$ & & & $100.0 \%$ & \\
Specificity & & $66.7 \%$ & & & $81.8 \%$ & \\
PPV & & $93.9 \%$ & & & $96.8 \%$ & \\
NPV & & $100.0 \%$ & & & $100.0 \%$ & \\
\hline
\end{tabular}

the standard histopathological and cytological analyses. Moreover, it can be used as a surveillance protocol during (and after) chemotherapeutic treatment to determine the appropriate time to stop (or restart) the chemotherapy where the cancer has regressed but left a bulk of fibrous tissue behind, such as in the chronic inflammation tissue of the penis after chemotherapy treatment (data not shown). In conclusion, the conventional histological and cytological based analyses should be performed along with the LINE-c-myc PCR assay to improve the accuracy of diagnosis. However, the tendency of false negative PCR results due to DNA degradation and/ or poor sample collection is not resolved, and further studies will focus on these issues.

ACKNOWLEDGMENTS. This research was supported by the Ratchadaphiseksomphot Endowment Fund of Chulalongkorn University (CU-58-001-HR). A Doctoral Degree Chulalongkorn University 100th Year Birthday Anniversary
Table 4. Signalment (age, sex, breed and status), anatomical sites and history of vincristine sulfate treatment in CTVT bearing dogs

\begin{tabular}{|c|c|c|}
\hline & Variable & Dogs \\
\hline \multirow{5}{*}{$\begin{array}{l}\text { Age (years) } \\
(\mathrm{n}=65)\end{array}$} & $<2$ & $2 / 34(5.9 \%)$ \\
\hline & 2 to 5 & $21 / 34(61.8 \%)$ \\
\hline & 6 to 9 & $6 / 34(17.7 \%)$ \\
\hline & $>9$ & $5 / 34(14.7 \%)$ \\
\hline & Unknown $(\mathrm{n}=37)$ & \\
\hline \multirow[t]{4}{*}{$\operatorname{Sex}(n=65)$} & Male/ intact & $26 / 64(40.0 \%)$ \\
\hline & Male/ castrated & $6 / 65(9.2 \%)$ \\
\hline & Female/ intact & $22 / 65(33.9 \%)$ \\
\hline & Female/ spayed & $11 / 65(16.9 \%)$ \\
\hline \multirow{4}{*}{$\begin{array}{l}\text { Breed group } \\
(\mathrm{n}=65)\end{array}$} & Mongrel & $62 / 65(95.4 \%)$ \\
\hline & Labrador retriever & $1 / 65(1.54 \%)$ \\
\hline & Poodle & $1 / 65(1.54 \%)$ \\
\hline & Siberian huski & $1 / 65(1.54 \%)$ \\
\hline \multirow[t]{2}{*}{ Status $(\mathrm{n}=65)$} & Homeless dog & $45 / 65(69.2 \%)$ \\
\hline & Owner (Free-ranging dog) & $20 / 65(30.8 \%)$ \\
\hline \multirow[t]{7}{*}{$\begin{array}{l}\text { Anatomical site } \\
\text { lesion }(n=65)\end{array}$} & $\begin{array}{l}\text { External genital area } \\
\text { (GTVT) }\end{array}$ & $39 / 65(60.0 \%)$ \\
\hline & Extragenital area (ETVT) & $26 / 65(40.0 \%)$ \\
\hline & - Skin & $12 / 26(46.2 \%)$ \\
\hline & - Nasal & $9 / 26(34.6 \%)$ \\
\hline & - Oral & $1 / 26(3.9 \%)$ \\
\hline & - Lymph node & $3 / 26(11.5 \%)$ \\
\hline & - Rectum & $1 / 26(3.9 \%)$ \\
\hline \multirow{2}{*}{$\begin{array}{l}\text { Previous history } \\
\text { of chemotherapy }\end{array}$} & Yes & $4 / 65$ (resistant) $(6.2 \%)$ \\
\hline & No & $61 / 65(93.9 \%)$ \\
\hline
\end{tabular}

Scholarship supported C. SETTHAWONGSIN. Some of this information was presented in the World Veterinary Con- 
gress (WVC) 2015 at Istanbul, Turkey and supported by the Overseas Presentations of Graduate Level Academic Thesis Scholarship.

\section{REFERENCES}

1. Amariglio, E. N., Hakim, I., Brok-Simoni, F., Grossman, Z., Katzir, N., Harmelin, A., Ramot, B. and Rechavi, G. 1991. Identity of rearranged LINE/c-MYC junction sequences specific for the canine transmissible venereal tumor. Proc. Natl. Acad. Sci. U.S.A. 88: 8136-8139. [Medline] [CrossRef]

2. Burnett, R. C., Vernau, W., Modiano, J. F., Olver, C. S., Moore, P. F. and Avery, A. C. 2003. Diagnosis of canine lymphoid neoplasia using clonal rearrangements of antigen receptor genes. Vet. Pathol. 40: 32-41. [Medline] [CrossRef]

3. Choi, Y. K. and Kim, C. J. 2002. Sequence analysis of canine LINE-1 elements and $\mathrm{p} 53$ gene in canine transmissible venereal tumor. J. Vet. Sci. 3: 285-292. [Medline]

4. Choi, Y., Ishiguro, N., Shinagawa, M., Kim, C. J., Okamoto, Y., Minami, S. and Ogihara, K. 1999. Molecular structure of canine LINE-1 elements in canine transmissible venereal tumor. Anim. Genet. 30: 51-53. [CrossRef] [Medline]

5. Das, U. and Das, A. K. 2000. Review of canine transmissible venereal sarcoma. Vet. Res. Commun. 24: 545-556. [Medline] [CrossRef]

6. Igor, U., Irena, C., Ksenija, I., Elena, A., Goran, N. and Plamen, T. 2012. Cytological diagnosis of canine transmissible venereal tumor-case report. Mac. Rev. Vet. 35: 91-96.

7. Katzir, N., Rechavi, G., Cohen, J. B., Unger, T., Simoni, F., Segal, S., Cohen, D. and Givol, D. 1985. "Retroposon" insertion into the cellular oncogene c-myc in canine transmissible venereal tumor. Proc. Natl. Acad. Sci. U.S.A. 82: 1054-1058. [Medline] [CrossRef]

8. Liao, K. W., Lin, Z. Y., Pao, H. N., Kam, S. Y., Wang, F. I. and Chu, R. M. 2003. Identification of canine transmissible venereal tumor cells using in situ polymerase chain reaction and the stable sequence of the long interspersed nuclear element. J. Vet. Diagn. Invest. 15: 399-406. [Medline] [CrossRef]

9. Lin, C. H., Chion, W. Y., Chuen, L. L., Shieh, L. E. and Chu, R. M. 2010. Deterioration and metastasis of a canine transmissible venereal tumor in a dog associated with a CPV-2. Taiwan Vet. J. 36: 191-200.

10. Marcos, R., Santos, M., Marrinhas, C. and Rocha, E. 2006. Cutaneous transmissible venereal tumor without genital involvement in a prepubertal female dog. Vet. Clin. Pathol. 35: 106-109. [Medline] [CrossRef]

11. Mozos, E., Méndez, A., Gómez-Villamandos, J. C., Martín De Las Mulas, J. and Pérez, J. 1996. Immunohistochemical characterization of canine transmissible venereal tumor. Vet. Pathol. 33: 257-263. [CrossRef] [Medline]

12. Mukaratirwa, S. and Gruys, E. 2003. Canine transmissible venereal tumour: cytogenetic origin, immunophenotype, and immunobiology. A review. Vet. Q. 25: 101-111. [Medline] [CrossRef]

13. Murchison, E. P. 2008. Clonally transmissible cancers in dogs and Tasmanian devils. Oncogene 27 Suppl 2: S19-S30. [Medline] [CrossRef]

14. Murgia, C., Pritchard, J. K., Kim, S. Y., Fassati, A. and Weiss, R. A. 2006. Clonal origin and evolution of a transmissible cancer. Cell 126: 477-487. [Medline] [CrossRef]

15. Parent, R., Teuscher, E., Morin, M. and Buyschaert, A. 1983. Presence of the canine transmissible venereal tumor in the nasal cavity of dogs in the area of dakar (senegal). Can. Vet. J. 24: 287-288. [Medline]

16. Park, M. S., Kim, Y., Kang, M. S., Oh, S. Y., Cho, D. Y., Shin, N. S. and Kim, D. Y. 2006. Disseminated transmissible venereal tumor in a dog. J. Vet. Diagn. Invest. 18: 130-133. [Medline] [CrossRef]

17. Pereira, J. S., Silva, A. B. F., Martins, A. L. B., Ferreira, A. M. R. and Brooks, D. E. 2000. Immunohistochemical characterization of intraocular metastasis of a canine transmissible venereal tumor. Vet. Ophthalmol. 3: 43-47. [Medline] [CrossRef]

18. Ponce, F., Marchal, T., Magnol, J. P., Turinelli, V., Ledieu, D., Bonnefont, C., Pastor, M., Delignette, M. L. and Fournel-Fleury, C. 2010. A morphological study of 608 cases of canine malignant lymphoma in France with a focus on comparative similarities between canine and human lymphoma morphology. Vet. Pathol. 47: 414-433. [Medline] [CrossRef]

19. Rungsipipat, A., Sunyasootcharee, B., Ousaewphlangchai, L., Sailasuta, A., Thanawongnuwech, R. and Teankum, K. 2003. Neoplasms of dogs in Bangkok. Thai J. Vet. Med. 33: 59-66. 